\title{
Prevalence of sexual violence in Ethiopian workplaces: systematic review and meta-analysis
}

\author{
Mulugeta Dile Worke ${ }^{1 *}\left(\mathbb{D}\right.$, Zewdie Birhanu Koricha ${ }^{2}$ and Gurmesa Tura Debelew ${ }^{3}$ (D)
}

\begin{abstract}
Background: Workplace sexual violence is a significant public health problem in low and middle-income countries, including Ethiopia. However, except for individual studies with varying prevalence rates in different occupations, there are no national prevalence studies conducted in workplace settings in Ethiopia. Appropriate estimation of the problem is essential to formulate health service plans most fitted for workplaces. Hence, this review and meta-analysis intended to estimate the national pooled prevalence of workplace sexual violence in Ethiopia.
\end{abstract}

Methods: The databases used were; PubMed, Google Scholar, CINAHL, and African Journals Online. For a critical appraisal of the papers, we used the Joanna Briggs Institute Meta-Analysis of Statistics Assessment and Review Instrument for cross-sectional studies. The meta-analysis was conducted using comprehensive meta-analysis and MetaXL software. Descriptive information of studies was presented in narrative form, and quantitative results were presented in forest plots. The Cochran $\mathrm{Q}$ test and $\mathrm{I}^{2}$ test statistics were employed to test heterogeneity across studies. A randomeffect model computed the pooled estimate prevalence with 95\% confidence intervals.

Results: The pooled prevalence of workplace sexual violence was $22 \%(95 \% \mathrm{Cl} 17 \%, 28 \%)$. The pooled prevalence was $14.1 \%(95 \% \mathrm{Cl} 10.4 \%, 18.9 \%)$ for attempted rape, $8 \%$ (95\% Cl 5.7\%, $11.1 \%)$ for rape, and $33.2 \%(95 \% \mathrm{Cl} 24.1 \%$, 43.7\%) for sexual harassment. The pooled prevalence was the highest among female university staffs $49 \%$ (95\% Cl $45 \%, 56 \%)$, and among commercial sex workers $28 \%$ (95\% Cl 3\%, 59\%).

Conclusions: This analysis revealed that the prevalence of sexual violence and sexual harassment in Ethiopian workplaces is high. It was also exceptionally high among female faculty staff, commercial sex workers, and workplaces in Tigray National regional state. Thus, concerned stakeholders must design and implement effective interventions to prevent workplace sexual violence in workplaces in Ethiopia and provide necessary support and care to the victims.

Keywords: Workplace sexual violence, Cross-sectional studies, Pooled prevalence, Ethiopia, Systematic review, Metaanalysis

\section{Plain English summary}

Workplace sexual violence (WSV) results in negative organizational culture, long-term health and psychological impacts on employees, damage to research integrity,

*Correspondence: muliedile@gmail.com

${ }^{1}$ Department of Midwifery, College of Health Sciences, Debre Tabor University, Debre Tabor, Ethiopia

Full list of author information is available at the end of the article and a costly loss of skilled workforce. It mainly affects workers in the most vulnerable work situations who have poor access to labor rights such as freedom of association, collective bargaining, decent work, non-discrimination, and access to justice. It also increases the likelihood of sexually transmitted infections, unintended pregnancies, and unsafe abortion. In Ethiopia, workplace sexual violence is one of the high burdens of sexual and reproductive health problems. The prevalence of workplace 
sexual violence varies from workplace to workplace and from occupation to occupation in Ethiopia. Poor knowledge of the impacts of workplace sexual violence prevention mechanisms, transactional sex practices, and poverty are the major contributors to WSV.

Recently, WSV is a significant public health and human right agenda in Ethiopia. However, a lack of national summarized data could be one reason for the poor implementation of sexual violence prevention and control programs in workplaces. Except for individual studies with varying prevalence rates, there are no national prevalence studies conducted in workplace settings in Ethiopia. Appropriate estimates of the problem are essential to formulate health service plans most fitted for workplace settings. The researchers investigated the prevalence of workplace sexual violence in different workplaces, and these studies were highly scattered by profession, geography, and occupation. These results indicate that individual studies should be reviewed and summarized for better utilization. Our systematic review and meta-analysis intended to fill this gap by calculating the pooled prevalence of workplace sexual violence in Ethiopian workplaces. We included 31 articles with 21,054 participants. Our systematic review and meta-analysis revealed that workplace sexual violence is a common public health problem in Ethiopia. In this systematic review and metaanalysis, $22 \%$ of the participants were workplace sexual violence victims. Of the types of WSV, workplace sexual harassment is high in Ethiopia. It is also exceptionally high among female university staff, commercial sex workers, and workplace in Tigray National Regional States. Thus, as noted above, governmental organizations and other relevant stakeholders should develop effective programs and interventions to reduce workplace sexual violence prevalence over different Ethiopian workplaces and protect victims with relevant legislation.

\section{Background}

Sexual violence (SV) is defined as "any sexual act, attempt to attain a sexual act, unwanted sexual comments or advances, or acts to traffic, or otherwise directed against, women's sexuality, using coercion (i.e., psychological intimidation, physical force, or threats of harm), by any person regardless of connection to the target, in any setting, including but not limited to home and work [1,2]" It is a societal issue that requires systemic change and is influenced by our larger social systems, including the workplace [3].

Workplace sexual violence (WSV) is part of workplace violence that takes verbal, non-verbal, and physical forms. It can be construed as unwanted, unreciprocated, or unwelcome behavior of a sexual nature tending to humiliate, threaten, or embarrass [4]. It includes sexual harassment, rape, and attempted rape [5]. Studies showed that women suffer physical, mental, and reproductive health consequences of sexual violence like depression, loss of self-confidence, injuries, unwanted pregnancy, sexually transmitted diseases, and disability up to death $[5,6]$. Another study indicated that rape alone results in about 32,000 unwanted pregnancies each year globally [7]. The problem can have an emotional impact and is linked to adverse health behaviors, such as substance use and mood disorders like anxiety and depression [8, 9].

The WSV mainly affects workers in the most vulnerable work situations who have poor access to labor rights such as freedom of association, collective bargaining, decent work, non-discrimination, and access to justice [10]. Although everyone has the right to live and work free from violence, sexual violence in the world of work exists in all occupations and sectors of the economy globally [11]. However, despite tremendous efforts, 1 in 3 (35\%) women are experiencing either physical or sexual violence, and 1 in 5 (20\%) experience rape or attempted rape worldwide in 2006 [12]. It is also one of the social inequalities across a broad range of cases and contexts. The power of WSV lies both in its ubiquity as a tool of domination and the ease with which it is rendered invisible [13].

Moreover, WSV has devastating effects on victims' health and well-being of victims and severe effects for the business owners and society [11]. It can fuel negative organizational culture [14]; it can result in long-term health and psychological impacts on employees and significant damage to research integrity, and a costly loss of skilled workforce in these fields [15]. Consequently, sustainable development goal five aims to achieve gender equality and empower all women and girls to encompass the elimination of all forms of violence against women and girls, and goal eight aims at full and productive employment and decent work for all [16]. However, there was uneven progress on gender equality, including decent work and freedom from violence [11].

Workplace sexual violence is a significant public health and human right agenda in Ethiopia [5]. However, a lack of national summarized data could be one reason for the poor implementation of sexual violence prevention and control programs in workplaces. Except for individual studies with varying prevalence rates, there are no national prevalence studies conducted in workplace settings in Ethiopia. Appropriate estimates of the problem are essential to formulate health service plans most fitted for workplace settings. The researchers investigated the prevalence of workplace sexual violence in different workplaces, and these studies were highly scattered by profession, geography, and occupation. These results indicate that individual studies should be reviewed and 
summarized for better utilization. Thus, this systematic review and meta-analysis intended to fill this gap by estimating the pooled prevalence of workplace sexual violence in workplaces in Ethiopia.

\section{Methods}

\section{Data sources and search strategy}

Grey literature deposited at universities and research institutes websites online repository and published studies in Ethiopia were searched. The electronic search of published studies was using PubMed, PubMed Central, MEDLINE, CINAHL, African Journals Online, Cochrane reviews databases and Google Scholar. All studies that reported workplace sexual violence in Ethiopia from July 1998 to June 5, 2020, were included in the review. The core search terms and phrases were "Workplace Violence", "sexual violence", "sex offense", "sexual abuse", "physical violence", "verbal violence", "sexual harassment", and "Ethiopia". The search strategies were developed using different Boolean operators. Notably, to fit the advanced PubMed central database, the following search strategy was applied: [Workplac* Violenc* OR sexual violenc*[MeSH Terms] OR sex offens*[MeSH Terms] OR sexual abus"[MeSH Terms] OR physical violenc* OR verbal violenc* OR sexual harassment AND Ethiopia]. Then we retrieved 1425 articles using this PubMed central searching strategy. To search PubMed, we used the following searching terms with Boolean operators; Workplace AND sexual violence OR physical violence OR verbal Violence OR sexual harassment AND Ethiopia. At this stage, we retrieved 152 articles. The included studies' references were also retrieved (Additional file 1). Similarly, articles that cited the identified critical articles were observed online (i.e., both ancestor and descendent search strategies were used). We screened the articles using the Preferred Reporting Items for Systematic Reviews and Meta-analyses (PRISMA) statement guidelines [17] (Fig. 1).

\section{Criteria for the consideration of studies for the review Inclusion criteria}

Design: All observational studies that measured the prevalence of workplace sexual violence in Ethiopia were included.

Publication status: All published studies and studies found on websites of Ethiopian universities and research institutes were included.

Language: Due to the feasibility of reading and understanding other languages and reporting articles in other languages is uncommon in Ethiopia. So only articles written in the English language were considered.

Publication or report year: Due to the insufficiency of literature on workplace sexual violence in Ethiopia, we reviewed all research reports from July 1998 until June 5, 2020.

Primary studies scored $\geq 60 \%$ of the Joanna Briggs Institute (JBI) criteria for evaluating the quality by two of the authors were included in the meta-analysis [18].

\section{Exclusion criteria}

Studies that reported sexual violence among refugees, married women, and pregnant women (intimate partner violence) were excluded due to the study's focus. Similarly, workplace violence studies that did not report workplace sexual violence and did not report workplace sexual violence prevalence or its types were excluded. Additionally, studies that used the workplace to identify participants for violence outside the workplace were excluded. Furthermore, pure qualitative studies assessed workplace sexual violence; reviews, essays, conference abstracts, letters, and commentaries were excluded from the study. Finally, when multiple publications from the same study population within the same year were identified, we included the publication that presented the complete information on results or the publication with the most significant number of cases.

\section{Operational definitions}

Workplace sexual violence is a situation where the employees are abused, threatened, intimidated to have sex or engage in acts of sex without their will in the circumstances related to their work and while commuting to and from work, involved explicit or implicit challenges to their safety, well-being, or health. It includes sexual harassment, attempted rape, and rape [5]. In this study, workplace sexual violence was considered if the primary studies report any type (sexual harassment, attempted rape, or rape). The direct report of workplace sexual violence was found and considered in some studies (Table 1).

Rape is any non-consensual penetration of the vagina, penetration obtained by physical body harm, by threatening or deception, or when the victim is unable to give consent [19].

Attempted rape is a trial to have sex without consent by coercion, threatening, or deception, or when the victim cannot consent, without the vagina's actual penetration [20].

Sexual harassment is defined as unwanted sexual behaviors, including jokes, verbal comments, and physical contacts intentionally done on women or girls [20].

\section{Data extraction and quality assessment}

We extracted the data using the Joanna Briggs Institute (JBI) tool for cross-sectional studies (Additional file 2) [21]. The tool contains information on study methods, results, and overall study details. The data extraction 


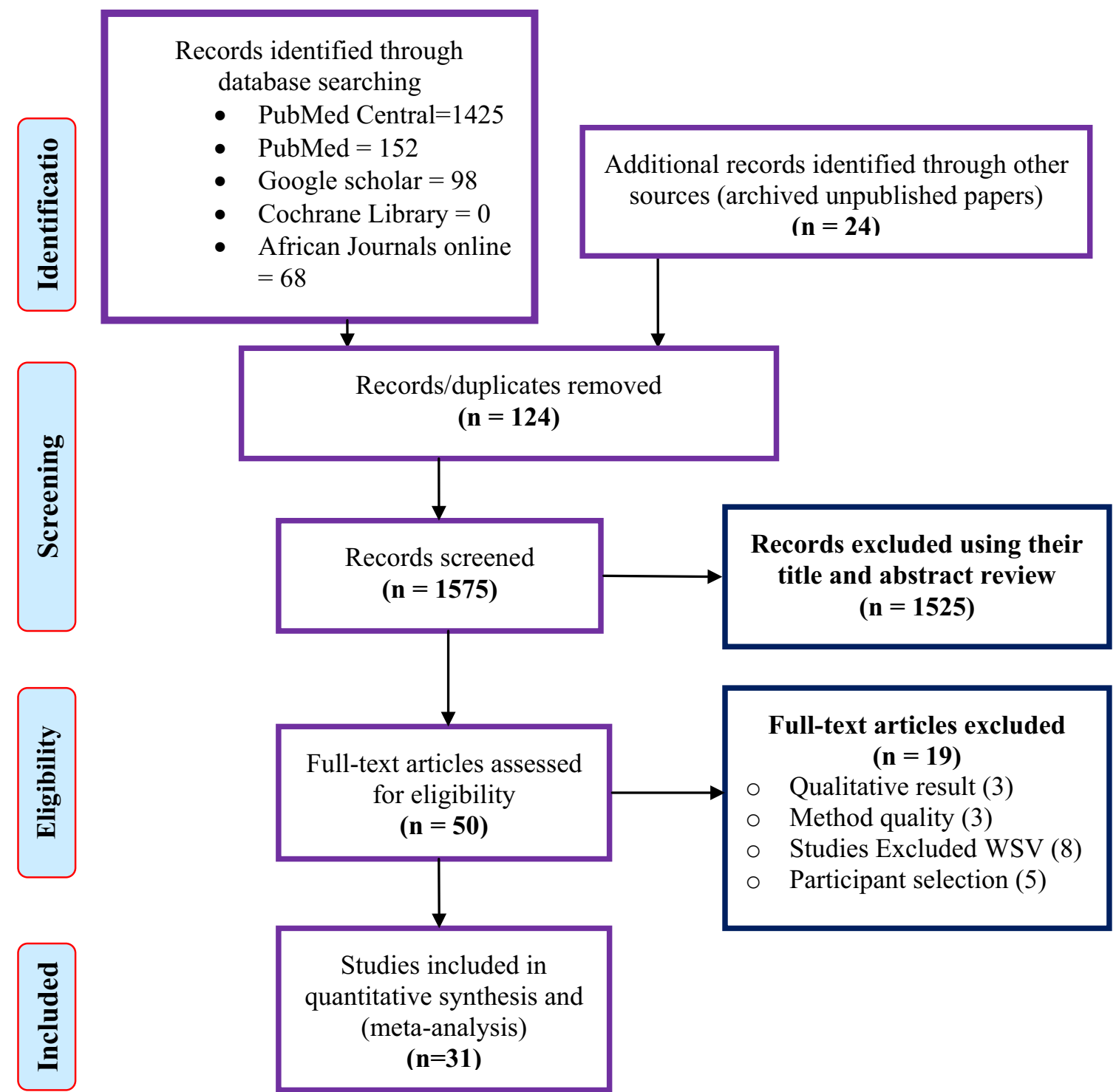

Fig. 1 Flow diagram of the included studies in the meta-analysis of workplace sexual violence in Ethiopia

tool also contains information on study period and year of publication, study area, region, study design and type, sample size, response rate, the prevalence of workplace sexual violence, and prevalence of different forms of workplace sexual violence. All selected articles, after a full review, were appraised using the JBI critical appraisal checklist. The metrics of quality assessment for the included studies were appropriateness of study participants (e.g., sampling frame, sampling procedure, and sample size), study settings, and designs (e.g., description of settings, analysis) as well as the appropriateness of measurements (e.g., validity, reliability). Two authors independently assessed the quality of included articles using the instrument. Any unclear information or disagreements were resolved through discussion. We used the mean quality score to assess the quality of included studies in the meta-analysis [22]. Accordingly, the quality score of the included studies ranged from 6 to 9 . The second and third authors were consulted for any discrepancies during the critical appraisal.

\section{Data analysis}

Data were analyzed using comprehensive meta-analysis version 3.0 and MetaXL version 5.3 software. We recalculated the unadjusted prevalence(waited) based on crude numerators and denominators provided by 
Table 1 List of the 31 studies and their subcategories included in the meta-analysis of workplace sexual violence in Ethiopia

\begin{tabular}{|c|c|c|c|c|c|c|c|c|c|c|}
\hline No & Study & Sample & SV & $\mathrm{SH}$ & AR & $\mathbf{R}$ & Occupation & Workplaces & Location & Sex \\
\hline 1 & Mulugeta et al. [67] & 1401 & - & 137 & 71 & 61 & Students & High School & Addis Ababa and West Shoa & $\mathrm{F}$ \\
\hline 2 & Worku and Addise [48] & 216 & 141 & - & 25 & 19 & Students & High School & Debark & $\mathrm{F}$ \\
\hline 3 & Tadesse $[68]^{\mathrm{a}}$ & 612 & - & 256 & 45 & 11 & Students & University & Addis Ababa & $\mathrm{F}$ \\
\hline 4 & Fitaw et al. [49] & 367 & - & 162 & 75 & 122 & Students & High School & Dabat & $\mathrm{F}$ \\
\hline 5 & Gebreyohannes [45] & 1024 & 352 & 217 & 197 & 57 & Students & High School & Mekelle & $\mathrm{F}$ \\
\hline 6 & Gorfu and Demise [65] & 301 & - & - & 50 & 61 & Students & High School & Jimma Zone & $\mathrm{F}$ \\
\hline 7 & Arnold et al. [53] & 1330 & 543 & & 102 & 33 & Students & University & Awassa & $\mathrm{F}$ \\
\hline 8 & Lelisa and Yusuf [69] & 377 & - & 286 & - & 98 & Students & High School & Addis Ababa & $\mathrm{F}$ \\
\hline 9 & Marsh et al. [54] & 387 & - & 181 & - & - & Faculty and Staff & University & Awassa & $\mathrm{F}$ \\
\hline 10 & Asfaw $[55]^{a}$ & 516 & - & 353 & 118 & 14 & Students & High School & Awassa & $\mathrm{F}$ \\
\hline 11 & Bekele et al. [64] & 764 & 520 & 398 & - & - & Students & High School & Dire Dawa, Harar, Jigjiga & $\mathrm{F}$ \\
\hline 12 & Haile et al. [70] & 872 & - & - & - & 38 & Students & High School & Addis Ababa & M \\
\hline 13 & Shimekaw et al. [50] & 536 & 202 & 192 & - & - & Students & University & Bahir Dar & $\mathrm{F}$ \\
\hline 14 & Tora [56] & 374 & - & 91 & 88 & 42 & Students & University & Wolayita Sodo & $\mathrm{F}$ \\
\hline 15 & Bekele and Deressa [57] & 590 & - & 242 & 37 & 12 & Students & University & Ambo & $\mathrm{F}$ \\
\hline 16 & Letta et al. [58] & 801 & - & - & 228 & 337 & Students & High School & Hadiya & $\mathrm{F}$ \\
\hline 17 & Takele and Setegn [59] & 397 & - & - & - & 27 & Students & University & Mada Walabu & $\mathrm{F}$ \\
\hline 18 & Alemayehu et al. [46] & 250 & 189 & 150 & - & - & CSW & Community & Mekelle & $\mathrm{F}$ \\
\hline 19 & Bekele et al. [74] & 605 & - & 221 & 152 & 66 & Students & University & Mada Walabu & $\mathrm{F}$ \\
\hline 20 & Fute et al. [60] & 642 & - & 84 & - & - & Nurses & $\mathrm{HF}$ & Awassa & B \\
\hline 21 & Jira [71] & 203 & - & 20 & - & - & Nurses & $\mathrm{HF}$ & Oromia Region & B \\
\hline 22 & Mamaru et al. [66] & 385 & - & 348 & - & - & Students & University & Jimma Zone & $\mathrm{F}$ \\
\hline 23 & Mulu et al. [51] & 124 & - & 36 & 25 & 16 & Students & High School & Debre Markos & $\mathrm{F}$ \\
\hline 24 & Nimani and Hamdela [61] & 332 & 55 & 14 & 4 & - & Students & High School & Butajira & $\mathrm{F}$ \\
\hline 25 & Sendo and Meleku [62] & 336 & - & - & - & 48 & Students & University & Awassa & $\mathrm{F}$ \\
\hline 26 & Adinew and Hagos [5] & 473 & 167 & - & - & - & Students & University & Wolayita Sodo & $\mathrm{F}$ \\
\hline 27 & Abate et al. [72] & 435 & - & 95 & - & - & $\mathrm{HCW}$ & $\mathrm{HF}$ & Addis Ababa & B \\
\hline 28 & Amogne et al. [73] & 4884 & - & - & - & 743 & CSW & Community & Ethiopia & $\mathrm{F}$ \\
\hline 29 & Yenealem et al. [52] & 531 & - & 38 & - & - & HCW & $\mathrm{HF}$ & Gondar Town & B \\
\hline 30 & Galu et al. [47] & 356 & 180 & - & - & - & Faculty and Staff & University & Mekelle & $\mathrm{F}$ \\
\hline 31 & Tantu [63] & 633 & 147 & - & - & 32 & Students & University & Wolayita Sodo & $\mathrm{F}$ \\
\hline Total & & 21,054 & 2496 & 3521 & 1217 & 1837 & & & & \\
\hline
\end{tabular}

AR attempted rape, Rrape, CSW commercial sex workers, $H C W$ Health care workers, $H F$ health facility, SH sexual harassment, SV sexual violence, $F$ female, $M$ male, $B$ both sexes

${ }^{\text {a }}$ Unpublished studies

individual studies. The study-specific prevalence variance was stabilized with the Freeman-Tukey double arcsine transformation before pooling the data within a random-effects meta-analysis model. This transformation was to minimize studies with extremely small or extensive prevalence estimates [28]. To assess the presence of publication bias Egger's asymmetry test was used [23]. A p-value $<0.05$ on the Egger test was considered indicative of statistically significant publication bias. Heterogeneity was assessed by the $x^{2}$ test Cochrane's $Q$ statistic [24], quantified by $\mathrm{H}$ and $\mathrm{I}^{2}$ values. The $\mathrm{I}^{2}$ statistic estimates the percent of total variation across studies due to actual differences between-study rather than luck. Generally, $\mathrm{I}^{2}$ values greater than $60-70 \%$ indicate substantial heterogeneity [25]. The source of variation between studies was assessed with subgroup analysis using stratifying variables such as outcome, study location/region, profession, workplace, and sex.

\section{Publication bias and heterogeneity}

The variation in the included studies, heterogeneity, was assessed by visual inspection of the forest plots. The $\mathrm{I}^{2}$ statistics and its corresponding $\mathrm{p}$-value were used to determine the statistical significance of heterogeneity. 
$\mathrm{I}^{2}$ statistics of $25 \%, 50 \%$, and $75 \%$ were used to declare low, moderate, and high heterogeneity, respectively [26]. For the valuation of the publication bias of the included studies, we used Funnel plots (Fig. 2). The publication bias's statistical significance was declared using the Egger regression asymmetry test, setting $\mathrm{p}<0.05[23,27]$. The Duval and Tweedie nonparametric trim and fill analysis using the random-effect analysis was conducted to account for publication bias for meta-analysis results, which showed the presence of publication bias (Egger test, $\mathrm{p}<0.05),[28]$. Moreover, to identify any possible outlier, sensitivity analysis (by removing each included study at a time) was carried out.

\section{Results}

\section{Study selection}

A total of 165 records (141 using the PUBMED database and 24 additional records identified from advanced google scholar, Cochrane review library, WHO databases, and gray literature from archives of universities in Ethiopia) related to the intended review topic were retrieved. Of these records, 139 studies remained after the removal of 26 duplicated retrievals. Of the 139 studies, 89 studies were excluded because they did not meet the study's inclusion criteria (JBI). Then, 50 full-text articles/reports were accessed and screened based on the pre-set criteria. Finally, the systematic review and meta-analysis included 31 studies that fulfilled the eligibility criteria (Table 1).

\section{Study characteristics}

Three studies, sexual violence, schooling, and silence, which is teacher narratives from a secondary school in Ethiopia [29], perceived risk factors for gender-based violence among Ethiopian university students [30], and resilience factors, causes and consequences of sexual abuse in housemaids working in Addis Ababa [31] were excluded due to lack of quantitative data for meta-analysis.

Eight studies [32-39] did not include sexual violence as an outcome, three studies [40-42] did not meet the JBI appraisal criteria, and five studies [33-35, 43, 44] were excluded due to the intention of selecting study participants (i.e., studies that base workplace to screen violence but the participants are not directly from the workplaces).

Out of the 31 studies that were eligible and included in the systematic review and meta-analysis, three studies were from north [45-47] and five studies from northwest Ethiopia [48-52]. Twelve studies from South Ethiopia [5, 53-63], one study from South East Ethiopia [64], and two studies from the South West $[65,66]$ parts of Ethiopia. Six studies from the central part of Ethiopia [67-72], one study on the 11 major cities [73], and one study from the western part of Ethiopia [57].

Regarding the study design, four studies were mixedmethod designs, and 27 were cross-sectional. In all studies, 22,176 samples planned, and 21,887 were responded, making an average response rate of $97.62 \%$. The sample

\section{Funnel Plot of Standard Error by Logit event rate}

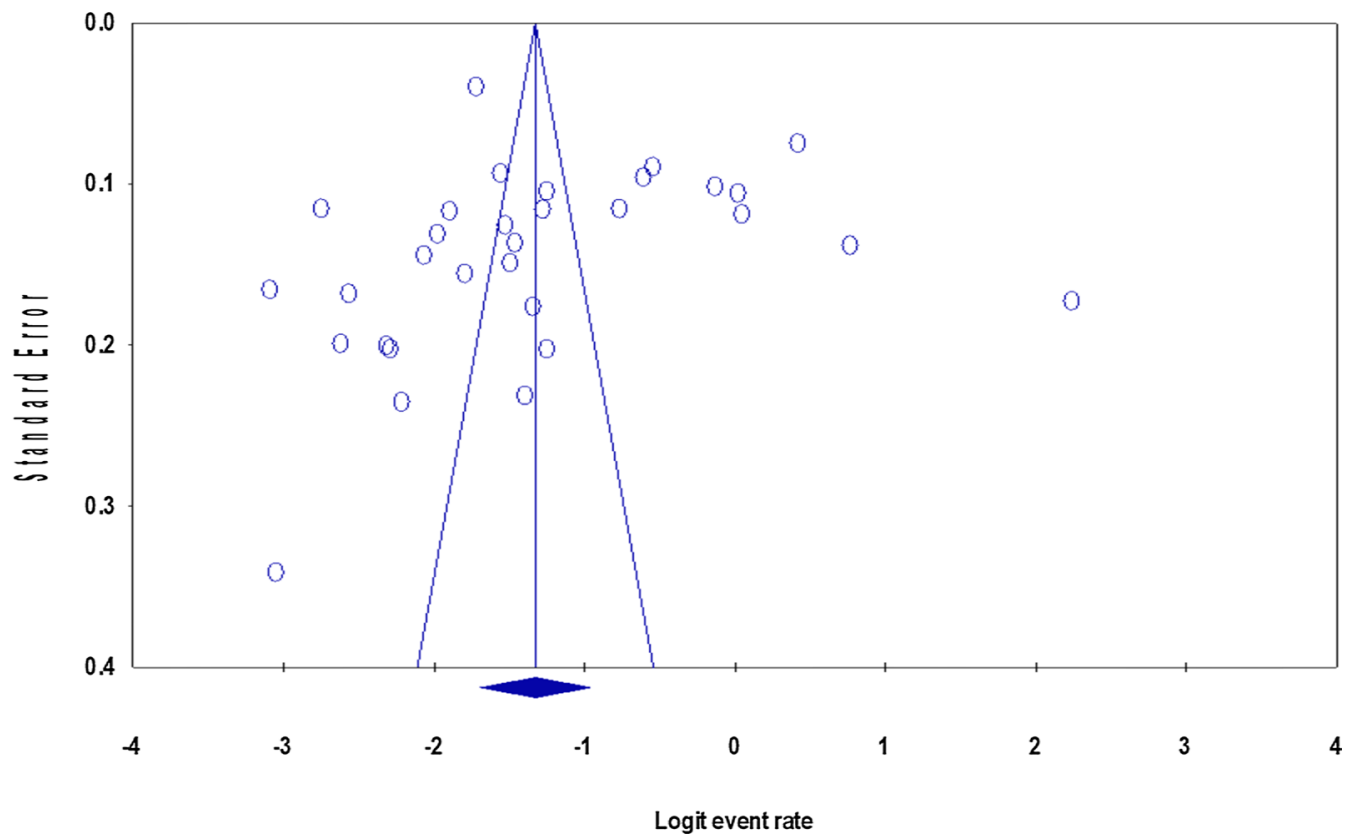

Fig. 2 Filled funnel plot of the 31 studies included in the meta-analysis of workplace sexual violence in Ethiopia 
size for each included study ranged from 124 in a study conducted in Debremarkos to 4900 in a study conducted among 11 major Ethiopian cities.

\section{Sensitivity analysis}

To identify smaller or larger pooled prevalence reports that could affect the pooled prevalence of sexual violence by giving a wide confidence interval and variance instability, we checked each study's sensitivity. However, it was found that no study significantly affected the pooled prevalence of sexual violence (Table 2).

\section{The pooled prevalence of workplace sexual violence}

Based on the random effect model, the overall pooled prevalence of WSV among the 21,054 respondents with a mean age of $22.22( \pm 3.15)$ years after combining each study outcome is $22 \%$ ( $95 \%$ CI $17,28 \%$ ). The heterogeneity test of included studies showed significant heterogeneity, $\mathrm{I}^{2}=99 \%$ and $\mathrm{p}<0.001$ (Fig. 3). Thus, subgroup analyses were conducted using occupation/profession, type of violence, workplace, and sex.

\section{Sub-group analysis}

After realizing the heterogeneity of the studies, subgroup analysis was conducted based on different characteristics. The subgroup analysis by profession showed the highest prevalence among female university staff (both academic and supportive) $49 \%$ (95\% CI 45, 56\%), followed by CSW 28\% (95\% CI 3, 59\%) (Fig. 4). Similarly, the pooled prevalence was $14.1 \%$ (95\% CI 10.4, $18.9 \%, \mathrm{p}<0.001)$ for

Table 2 The summary of sensitivity analysis of the included studies

\begin{tabular}{|c|c|c|c|c|}
\hline Study & Pooled P (95\% Cl) & Cochrane Q & p-value & $\mathrm{I}^{2}(95 \% \mathrm{Cl})$ \\
\hline Mulugeta et al. [67] & $22.9(17.1,29.3)$ & 2960.405 & $<0.001$ & $99.020(98.884,99.140)$ \\
\hline Worku and Addise [48] & $22.2(16.4,28.6)$ & 3199.319 & $<0.001$ & $99.094(98.971,99.202)$ \\
\hline Tadesse $[68]^{* *}$ & $22.7(16.8,29.2)$ & 3152.117 & $<0.001$ & $99.080(98.954,99.190)$ \\
\hline Fitaw et al. [49] & $21.9(16.1,28.3)$ & 3167.142 & $<0.001$ & $99.084(98.960,99.194)$ \\
\hline Gebreyohannes [45] & $22.4(16.4,29.0)$ & 3199.695 & $<0.001$ & $99.094(98.971,99.202)$ \\
\hline Gorfu and Demise [65] & $22.3(16.5,28.8)$ & 3201.051 & $<0.001$ & $99.094(98.971,99.202)$ \\
\hline Arnold et al. [53] & $22.4(16.4,29.0)$ & 3200.272 & $<0.001$ & $99.094(98.971,99.202)$ \\
\hline Lelisa and Yusuf [69] & $21.4(15.8,27.6)$ & 3013.904 & $<0.001$ & $99.038(98.904,99.155)$ \\
\hline Marsh et al. [54] & $21.5(15.9,27.7)$ & 3054.824 & $<0.001$ & $99.051(98.920,99.166)$ \\
\hline Asfaw $[55]^{* *}$ & $22.3(16.4,28.7)$ & 3199.788 & $<0.001$ & $99.094(98.971,99.202)$ \\
\hline Bekele et al. [64] & $21.1(15.9,26.9)$ & 2584.692 & $<0.001$ & $98.878(98.714,99.021)$ \\
\hline Haile et al. [70] & $23.0(17.2,29.4)$ & 2996.146 & $<0.001$ & $99.032(98.898,99.150)$ \\
\hline Shimekaw et al. [50] & $21.8(16.0,28.1)$ & 3110.590 & $<0.001$ & $99.068(98.940,99.180)$ \\
\hline Tora [56] & $22.3(16.5,28.8)$ & 3201.074 & $<0.001$ & $99.094(98.971,99.202)$ \\
\hline Bekele and Deressa [57] & $22.7(16.8,29.2)$ & 3151.395 & $<0.001$ & $99.080(98.954,99.190)$ \\
\hline Letta et al. [58] & $22.6(16.7,29.1)$ & 3173.202 & $<0.001$ & $99.086(98.962,99.196)$ \\
\hline Takele and Setegn [59] & $22.8(17.0,29.3)$ & 3146.895 & $<0.001$ & $99.078(98.953,99.189)$ \\
\hline Alemayehu et al. [46] & $21.6(15.9,27.9)$ & 3128.377 & $<0.001$ & $99.073(98.946,99.185)$ \\
\hline Bekele et al. [74] & $22.2(16.3,28.7)$ & 3196.346 & $<0.001$ & $99.093(98.970,99.201)$ \\
\hline Fute et al. [60] & $22.6(16.7,29.1)$ & 3185.006 & $<0.001$ & $99.089(98.966,99.198)$ \\
\hline Jira [71] & $22.7(16.8,29.2)$ & 3187.969 & $<0.001$ & $99.090(98.967,99.199)$ \\
\hline Mamaru et al. [66] & $20.2(15.5,25.3)$ & 2183.174 & $<0.001$ & $98.972(98.465,98.851)$ \\
\hline Mulu et al. [51] & $22.3(16.5,28.8)$ & 3200.941 & $<0.001$ & $99.094(98.971,99.202)$ \\
\hline Nimani and Hamdela [61] & $23.0(17.1,29.4)$ & 3128.856 & $<0.001$ & $99.073(98.946,99.185)$ \\
\hline Sendo and Meleku [62] & $22.5(16.6,29.0)$ & 3196.198 & $<0.001$ & $99.093(98.969,99.201)$ \\
\hline Adinew and Hagos [5] & $21.8(16.1,28.2)$ & 3132.768 & $<0.001$ & $99.074(98.948,99.186)$ \\
\hline Abate et al. [72] & $22.2(16.4,28.7)$ & 3198.478 & $<0.001$ & $99.093(98.970,99.202)$ \\
\hline Amogne et al. [73] & $22.4(16.0,29.6)$ & 3142.350 & $<0.001$ & $99.077(98.951,99.188)$ \\
\hline Yenealem et al. [52] & $22.8(17.0,29.3)$ & 3133.164 & $<0.001$ & $99.074(98.948,99.186)$ \\
\hline Galu et al. [47] & $21.4(15.8,27.6)$ & 3031.239 & $<0.001$ & $99.043(98.911,99.160)$ \\
\hline Tantu [63] & $22.6(16.7,29.1)$ & 3171.915 & $<0.001$ & $99.086(98.961,99.195)$ \\
\hline
\end{tabular}

**Unpublished studies 


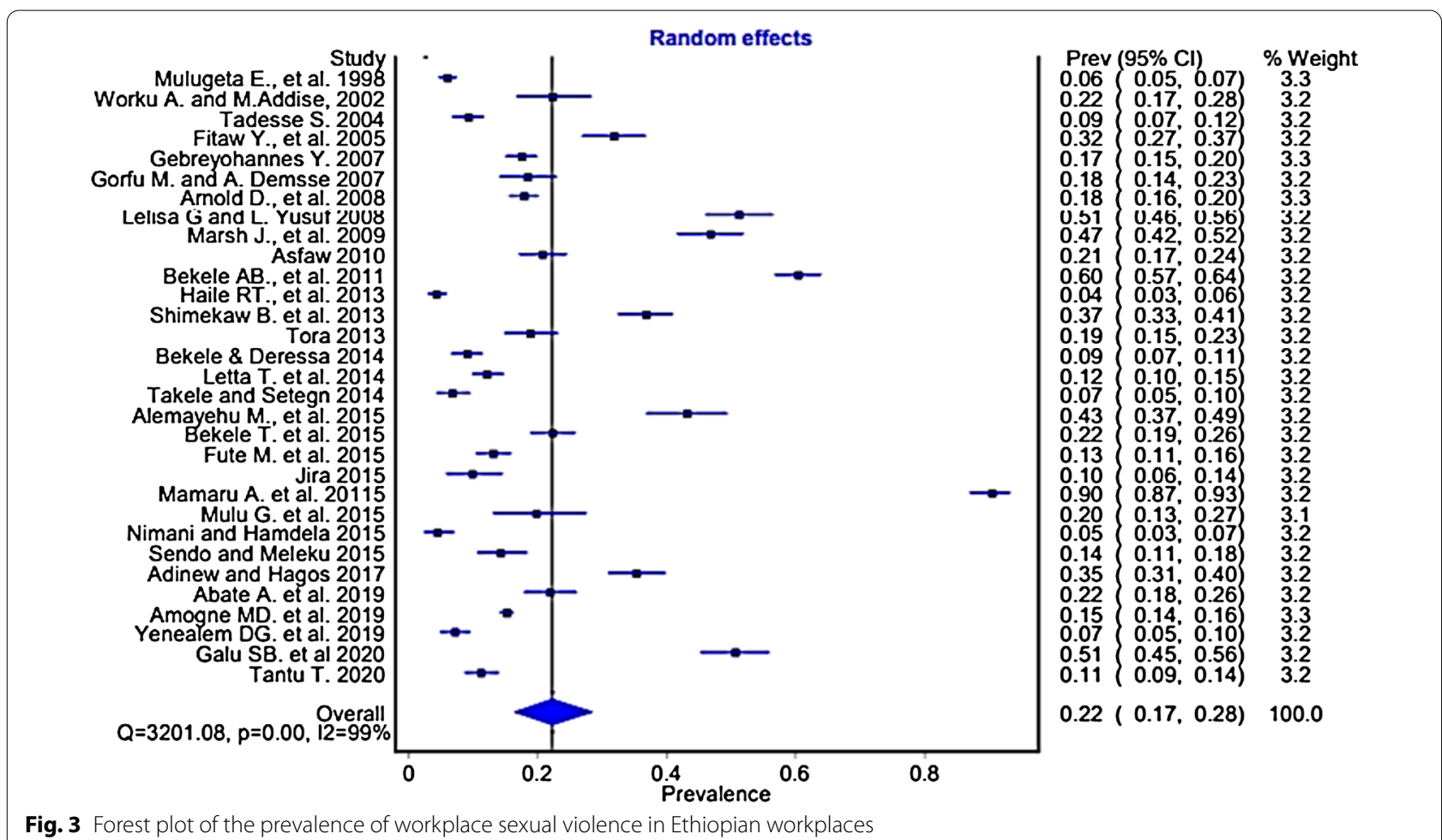

attempted rape, $8 \%$ (95\% CI 5.7, 11.1\%, p<0.001) for rape, and $33.2 \%$ (95\% CI 24.1, 43.7\%, p=0.002) for $\mathrm{SH}$ (Table 3).

Based on study location, Tigray national regional state had the highest prevalence of pooled WSV $36.1 \%$ (95\% CI $12.8 \%$ to $61.5 \%$ ), followed by Oromia national regional state $24.1 \%$ (95\%CI $1.7 \%$ to $52.3 \%$ ), Amhara national regional state $22.6 \%$ (95\% CI $10 \%$ to $36.8 \%$ ), Addis Ababa $18.8 \%$ (95\% CI $2.2 \%$ to $40 \%$ ), and SNNPR $18.2 \%(95 \%$ CI $12.2 \%$ to $24.9 \%)$. The pooled prevalence of crossregional studies was $23.9 \%$ (95\% CI $2 \%$ to $51.5 \%$ ). The pooled prevalence of WSV was $20.9 \%$ (95\% CI $16.8 \%$ to $25.7 \%)$ among studies that reported SV among females only, and $12.2 \%$ (95\% CI $7.4 \%$ to $19.6 \%$ ) among studies that reported SV in both sexes (Table 3). On the other hand, the pooled WSV prevalence among female CSW $28 \%(95 \%$ CI 3,59\%), and university students $27 \%(95 \%$ CI 15,39\%) were the highest (Fig. 5).

\section{Discussion}

This systematic review and meta-analysis indicated that the pooled prevalence of workplace sexual violence in Ethiopia was $22 \%$ ranging from 17 to $28 \%$. This finding was higher than the prevalence of workplace violence among Korean employees [75] and American employees [76]. However, it was lower than workplace sexual violence among Nigerian employees (63.8\%) [77]. The differences in definitions and classifications used, differences in methodologies for collecting and processing information, differences in time frames analyzed, and differences in culture in the experience of violence and harassment might delimit the concept of WSV. So, it is challenging to compare statistics on exposure to workplace sexual violence across different countries. The difference might be due to the difference in workplaces [78] in Ethiopia and the countries mentioned above. The countries mentioned above, including Ethiopia, prohibited workplace sexual violence. So, the difference in the prevalence of WSV between Korea, the USA, Nigeria, and Ethiopia are probably not due to Anti-violence (harassment) laws. This study might be different due to methodological, setting, population difference, development status, and law enforcement between Korea, the USA, and Ethiopia. We encountered one challenge while conducting this study because more primary studies were conducted among educational settings, and few on university staff, commercial sex workers, nurses, and general health care workers. This finding indicates that the concept of workplace violence is entirely new in Ethiopian society, and there are no regulations or policy interventions specific to violence in the workplace. This result may result in reduced sensitivity to the perception of workplace violence in Ethiopia. 


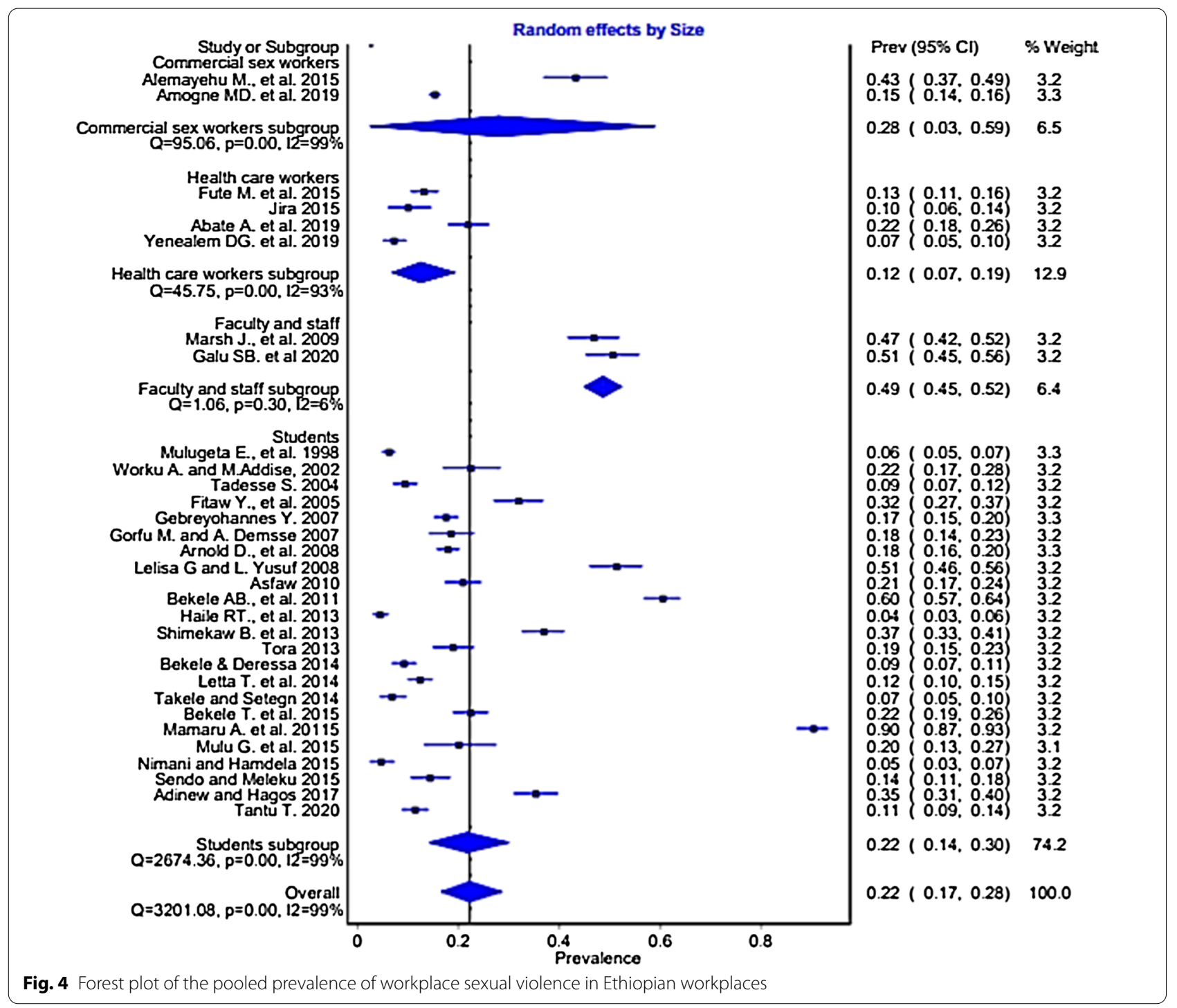

The sub-group analysis of WSV by type in our study indicated that the pooled prevalence was $14.1 \%, 8 \%$, and $33.2 \%$ for attempted rape, rape, and sexual harassment, respectively. These findings were lower than the Nigerian study [77] and higher than the Korean study [75]. The differences in the prevalence estimates of sexual violence types might be due to the difference in method. Though it reports all forms of workplace sexual violence, the Nigerian national study was cross-sectional with a small sample of participants from different professions. However, ours is a systematic review and meta-analysis with a large sample of participants. This systematic review and meta-analysis finding implies that legislation and prohibitions of only sexual harassment might not be adequate to address all the forms of WSV occurring in the Ethiopian workplace context. Thus, we suggest the necessity for better protection actions against workplace sexual violence to create a safe working environment for Ethiopian employees. We also would like to recommend all workplaces to implement the proclamation set by the Ethiopian ministry of labor and social affairs.

It also indicated that the pooled prevalence of workplace sexual violence was high among female employees (20.9\%). The finding was not in line with the previous systematic review [79]. However, the previous study finding was focused on the physical violence of workplaces. The subgroup analysis also indicated that the pooled prevalence of workplace sexual violence among health care professionals was $12 \%$ (95\% CI $7 \%$ to $19 \%$ ), which is similar to the previous systematic review and meta-analysis [80]. This finding is higher than the workplace sexual violence in America [76] and China [81]. One of the crucial reasons for the study differences might be the difference 
Table 3 Stratified analysis of the 31 studies included a meta-analysis based on the outcome, sex, and Ethiopian regions

\begin{tabular}{lccc}
\hline Stratifying variable & Sample size & Fixed effects $\mathbf{P}(\mathbf{9 5} \% \mathbf{C l})$ & Random effects $\mathbf{P}(\mathbf{9 5} \%)$ \\
\hline Outcomes & & & $0.141(0.104,0.189)$ \\
Attempted rape & 1217 & $0.183(0.174,0.193)$ & $0.080(0.057,0.111)$ \\
Completed rape & 1837 & $0.124(0.119,0.130)$ & $0.332(0.241,0.437)$ \\
Sexual harassment & 3521 & $0.364(0.354,0.375)$ & $0.122(0.074,0.196)$ \\
Sex & & & $0.209(0.168,0.257)$ \\
Both & 1811 & $0.141(0.125,0.158)$ & $0.044(0.032,0.059)$ \\
Female & 18,371 & $0.277(0.272,0.283)$ & \\
Male (1 study) & 872 & $0.044(0.032,0.059)$ & $0.361(0.128,0.615)$ \\
Location & & & $0.226(0.100,0.368)$ \\
Tigray & 1630 & $0.276(0.034,0.567)$ & $0.241(0.017,0.523)$ \\
Amhara & 1774 & $0.226(0.088,0.381)$ & $0.182(0.122,0.249)$ \\
Oromia & 2481 & $0.238(0.007,0.538)$ & $0.188(0.022,0.400)$ \\
SNNPR & 5787 & $0.177(0.110,0.249)$ & $0.239(0.020,0.515)$ \\
Addis Ababa & 2296 & $0.142(0.000,0.345)$ & $0.169(0.000,0.499)$ \\
Cross region & 7048 & & \\
\hline
\end{tabular}

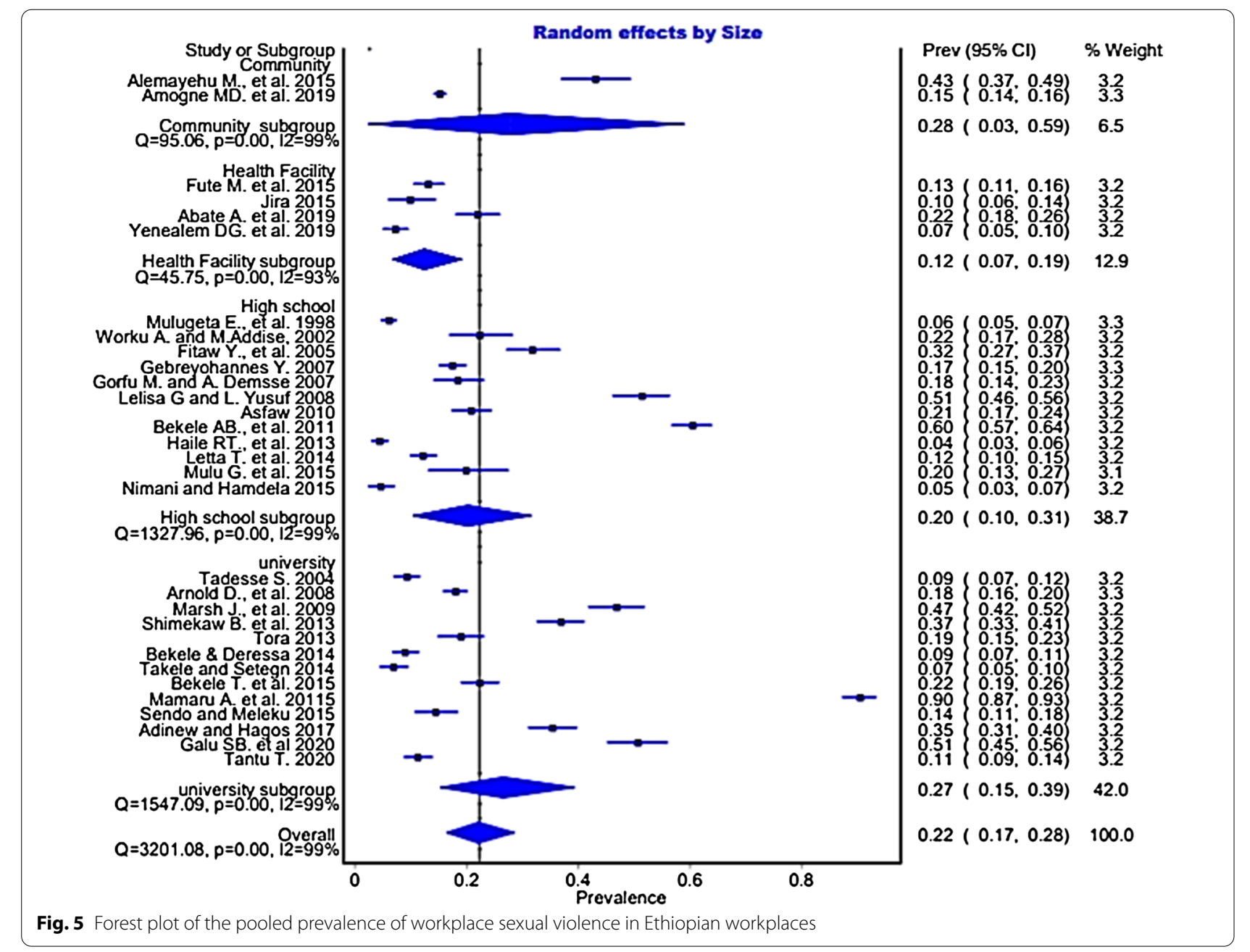


in the measurement of sexual violence, sociodemographic status, culture, and study methods.

At the same time, workplace sexual violence among commercial sex workers was $28 \%$ (95\% CI $3 \%$ to $59 \%$ ), which is consistent with the previous global systematic review [82] that ranged from 32 to $55 \%$, studies in Mexican cities (11.7\%) [83], and with a study conducted in Northern Uganda (49\%) [84]. This finding was similar due to the similarity of socioeconomic characteristics, work context, social and behavioral characteristics of female commercial sex workers. In the meantime, our study's findings share common problems of LMICs, including Uganda and Mexico. It implies that there could be poverty, childhood abuse history, police abuse, high rates of STIs [85], and high rates of drug and alcohol use [86-91], which needs the development of evidence-based HIV/STI prevention programs and treatment services for this high-risk population [84].

In line with a recent global systematic review among staff in higher education [92], the pooled prevalence of workplace sexual violence among female faculty, including the staff, was high in this study, $49 \%$ ranging from 45 to $56 \%$. This study finding is similar to the study findings in Nepal (53.8\%) [93] and Malaysia (52.7\%) [94]. It is slightly higher than the finding of the study conducted in Lebanon (41.9\%) [95]. It is also lower than the study conducted in America (68\%) [96]. The difference might be considering any action against women as sexual Violence in Ethiopian studies and the variations in socioeconomic status, sociodemographic variables of the study participants, and sample size. However, there is still no adequate information on the prevalence and resulting health effects of workplace sexual violence among female faculty and staff in the academic settings of LMICs. Therefore, there is no adequate knowledge to draw from and clarify tendencies in the data.

Similarly, the sub-group analysis using the profession in this study indicated that the pooled workplace sexual violence was $22 \%$ among students. Specific to the education settings' location, the pooled prevalence was $20 \%$ in high school and $27 \%$ in universities. In this systematic review and meta-analysis, more primary studies were included from education settings than other workplaces (23 studies, 13 at universities and ten at high school level), which indicated that more primary studies were conducted in education settings in Ethiopia. This systematic review and meta-analysis study identified a discrepancy of sexual violence prevalence from study to study (6\% [61] to $90 \%$ [66]). This finding was similar to the previous global systematic review finding [97]. This study's findings conclude that sexual violence in education centers (both in high school and Universities) is a considerable concern in Ethiopia. Thus, in addition to the need to conduct longitudinal cohorts and more comprehensive follow-up studies, this study suggests the design of suitable preventive measures, development of inter-cultural research projects involving different regions, and consideration of social norms, sense of community, pro-social modeling, organizational policies, and the physical environment of educational centers' beyond the individual, group, and situational levels for future researchers in line with a previous systematic review [98].

Furthermore, in the sub-group analysis based on regional states, the pooled prevalence of workplace sexual violence was high in the Tigray regional state (36.1\%) and low in Addis Ababa city (18.8\%) and SNNPR (18.2\%) region. However, it was almost similar in the Amhara National Regional State (22.6\%), in the Oromia National Regional State (24.1\%), and cross-regional studies (23.9\%). The low prevalence estimates in the Addis Ababa city and SNNPR region could be due to better awareness of sexual violence practices in workplaces. The high prevalence from the Tigray region could be because a study with high prevalence among commercial sex workers and female administrative staff was included in the study that might affect the overall pooled prevalence estimate in that area. Besides, the studies conducted in Tigray's regional state were only from a single city (Mekelle). Thus, this study suggests that researchers conduct more studies in different parts of the region and suggest the region consider implementing gender policy and rules and regulations that safeguard employees from sexual violence. Moreover, there is a need to develop interventions that could empower women employees, control and monitor the law's implementation, create awareness for men, and develop organizational anti-sexual violence policies.

The critical policy implication of this study findings relies on the prevention and control of workplace sexual violence. These findings suggest that it is essential to implement strategies to reduce workplace sexual violence prevalence over different workplaces. Similar to the recommended strategies suggested to reduce general workplace violence, adequate staffing, and education and training programs are essential to assist employees and students. Similarly, public awareness creates workplace sexual violence negativity through a mass media campaign, enforcing appropriate policies and legislation, such as encouraging staff to report such acts and judicial punishment on the perpetrators promptly. It is mandatory to apply preventive strategies urgently among workplaces, particularly the universities, to reduce the negative impacts of workplace sexual violence among employees. This study's finding is an essential input for governmental organizations (Ministry of Health, Ministry of social and labor affairs, Ministry of women and child, general 
attorney), non-governmental organizations (both local and international), and other relevant stakeholders such as civic societies who want to work on limiting and reducing workplace sexual violence. However, there is a need to conduct more primary studies in other professions and workplaces, such as hospitality workplaces, industrial parks, and factories, that leads the world's workplace sexual violence report.

We need to mention some potential limitations of this systematic review and meta-analysis. Although the number of primary studies for estimating workplace sexual violence prevalence was adequate, it was more among education settings than other jobs. Second, due to the differences in associated factors based on the profession and workplaces, this study did not include the review of associated factors. Third, this study was the first to estimate the pooled prevalence of any WSV and incorporated all types of WSV in Ethiopia; however, the primary studies on sexual violence were conducted on limited professions (see Table 1).

\section{Conclusions}

This review and meta-analysis indicated that the prevalence of sexual violence in Ethiopian workplaces is high. Of the types of workplace sexual violence, workplace sexual harassment is high. It is also exceptionally high among female university staff, commercial sex workers, and Tigray regional state workplaces. Governmental organizations, non-governmental organizations, and other stakeholders should develop effective programs and interventions to reduce workplace sexual violence prevalence over different (students, commercial sex workers, nurses, health care workers, university staffs) Ethiopian workplaces. Also, the prevention of sexual violence in the workplace is possible but cannot be fully realized without understanding the problem. Therefore, conducting more primary studies of workplace sexual violence in different workplace settings, particularly in hospitality workplaces, which leads the report of WSV worldwide, using nationally representative data is essential to understand this problem's potential magnitude and the most common forms of sexual violence perpetrated to inform prevention efforts. Also, examining the impacts of these forms of violence provides some additional context and uncovers the adverse health effects this kind of sexual violence has on victims. Moreover, bringing attention to and better contextualizing these workplace sexual violence experiences would increase the Ethiopian context's ability to prevent them.

\section{Supplementary information}

Supplementary information accompanies this paper at https://doi. org/10.1186/s12978-020-01050-2.

Additional file 1. Database searching strategies.

Additional file 2. Joanna Briggs Institute (JBI) tool for appraisal of crosssectional studies.

\section{Abbreviations}

AR: Attempted rape; Cl: Confidence interval; CMA: Comprehensive metaanalysis; CR: Completed rape; CSW: Commercial sex workers; HCW: Health care workers; HF: Health facility; ILO: International Labor Organization; JBI: Joanna Briggs Institute; PRISMA: Preferred Reporting Items for Systematic Reviews and Meta-analyses; SH: Sexual harassment; SNNPR: South nations and nationalities of people region; SPSS: Statistical package for social sciences; SV: Sexual violence; UN: United Nations; WSV: Workplace sexual violence.

\section{Acknowledgements}

We would like to forward our deepest gratitude to all sources of primary studies.

\section{Authors' contributions}

MD, GT, and ZB conceived the design, select and assess the quality of studies, extract data, interpret the findings, and wrote the manuscript. All authors also develop the search strategies, and GT and ZB gave advice on meta-analysis methodology and contributed to reviewing or revising the paper. All authors read and approved the final manuscript.

\section{Funding}

We author declared that we did not obtain funding for this research from any source.

Availability of data and materials

All data generated or analyzed are included in the results of the document.

Ethics approval and consent to participate

Not applicable.

Consent for publication

Not applicable.

\section{Competing interests}

All authors confirm that they have no competing interests.

\section{Author details}

${ }^{1}$ Department of Midwifery, College of Health Sciences, Debre Tabor University, Debre Tabor, Ethiopia. ${ }^{2}$ Department of Health, Behavior, and Society, Faculty of Public Health, Jimma University, Jimma, Ethiopia. ${ }^{3}$ Department of Population and Family Health, Faculty of Public Health, Jimma University, Jimma, Ethiopia.

Received: 3 September 2020 Accepted: 25 November 2020

Published online: 09 December 2020

\section{References}

1. Sen P, Jewkes R, Garcia-Moreno C. Sexual violence. 2002.

2. Jewkes R, Dartnall E. More research is needed on digital technologies in violence against women. Lancet Public Health. 2019;4(6):e270-1.

3. Jewkes R, Dartnall E. Sexual violence. In: International encyclopedia of public health. Ed. 2017. p. 491-8. 
4. Cheung T, Yip PS. Workplace violence towards nurses in Hong Kong: prevalence and correlates. BMC Public Health. 2017;17(1):196.

5. Adinew YM, Hagos MA. Sexual violence against female university students in Ethiopia. BMC Int Health Hum Rights. 2017;17(1):19.

6. Heise L, Ellsberg M, Gottmoeller M. A global overview of gender-based violence. Int J Gynecol Obstet. 2002;78:S5-14.

7. Gossaye Y, Deyessa N, Berhane Y, Ellsberg M, Emmelin M, Ashenafi M, Alem A, Negash A, Kebede D, Kullgren G. Women's health and life events study in rural Ethiopia. Ethiop J Health Dev. 2003;17(5).

8. Walsh K, Keyes KM, Koenen KC, Hasin D. Lifetime prevalence of genderbased violence in US women: associations with mood/anxiety and substance use disorders. J Psychiatr Res. 2015;62:7-13.

9. Deyessa N, Berhane Y, Alem A, Ellsberg M, Emmelin M, Hogberg U, Kullgren $\mathrm{G}$. Intimate partner violence and depression among women in rural Ethiopia: a cross-sectional study. Clin Pract Epidemiol Ment Health. 2009;5(1):8.

10. Pillinger J. Violence and harassment against women and men in the world of work. Geneva: International Labor Organisation; 2017.

11. Women U. Handbook: addressing violence and harassment against women in the world of work; 2019.

12. Ellsberg M. Violence against women and the millennium development goals: facilitating women's access to support. Int J Gynecol Obstet. 2006;94(3):325-32

13. Armstrong EA, Gleckman-Krut M, Johnson L. Silence, power, and inequality: an intersectional approach to sexual violence. Ann Rev Sociol. 2018;44:99-122.

14. Johnson P. Sexual harassment of women. Climate, culture, and consequences in academic sciences, engineering, and medicine. A consensus study report of the National Academic of Sciences, Engineering, and Medicine. Washington DC, National Academies Press. 2018.

15. National Academies of Sciences E, Medicine. Sexual harassment of women: climate, culture, and consequences in academic sciences, engineering, and medicine. Washington DC: National Academies Press; 2018.

16. Assembly G. Sustainable development goals. SDGs Transforming Our World. 2015, 2030.

17. Moher D, Liberati A, Tetzlaff J, Altman DG. Preferred reporting items for systematic reviews and meta-analyses: the PRISMA statement. Int J Surg. 2010;8(5):336-41.

18. Munn Z, Moola S, Lisy K, Riitano D, Tufanaru C. Methodological guidance for systematic reviews of observational epidemiological studies reporting prevalence and cumulative incidence data. Int J Evid-based Healthc. 2015;13(3):147-53.

19. Assembly G. United Nations General Assembly, Declaration on the Elimination of Violence Against Women.

20. Organization WH. Putting women first: ethical and safety recommendations for research on domestic violence against women. Geneva: World Health Organization; 2001.

21. Tufanaru C. Chapter 3: Systematic reviews of effectiveness. In: Aromataris E, Munn Z, editors. Joanna Briggs Institute Reviewer's Manual. Adelaide: The Joanna Briggs Institute; 2017

22. Abajobir AA, Kisely S, Maravilla JC, Williams G, Najman JM. Gender differences in the association between childhood sexual abuse and risky sexual behaviors: a systematic review and meta-analysis. Child Abuse Negl. 2017:63:249-60.

23. Egger M, Smith GD, Schneider M, Minder C. Bias in meta-analysis detected by a simple, graphical test. BMJ. 1997;315(7109):629-34

24. Cochran WG. The combination of estimates from different experiments. Biometrics. 1954;10(1):101-29.

25. Higgins JP, Thompson SG. Quantifying heterogeneity in a meta-analysis. Stat Med. 2002;21(11):1539-58.

26. Higgins JP, Thompson SG, Deeks JJ, Altman DG. Measuring inconsistency in meta-analyses. BMJ. 2003;327(7414):557-60.

27. Begg CB, Mazumdar M. Operating characteristics of a rank correlation test for publication bias. Biometrics. 1994:1088-1101.

28. Duval S, Tweedie R. Trim and fill: a simple funnel-plot-based method of testing and adjusting for publication bias in meta-analysis. Biometrics. 2000;56(2):455-63.

29. Altinyelken HK, Le Mat M. Sexual violence, schooling, and silence: teacher narratives from a secondary school in Ethiopia. Comp J Comp Int Educ. 2018;48(4):648-64.
30. Kaufman MR, Williams AM, Grilo G, Marea CX, Fentaye FW, Gebretsadik LA, Yedenekal SA. We are responsible for the violence prevention is up to us: a qualitative study of perceived risk factors for gender-based violence among Ethiopian university students. BMC Women's Health. 2019;19(1):131.

31. Ayenalem S. Causes and consequences of sexual abuse and resilience factors in housemaids working in Addis Ababa: a qualitative inquiry. Ethiop J Soc Sci. 2015;1(1).

32. Terefe $D$, Mengistu D. Violence in Ethiopian schools: a study of some schools in Addis Ababa. Violence at school: global issues and interventions. Paris: UNESCO; 1997.

33. Lakew Z. Alleged cases of sexual assault reported to two Addis Ababa hospitals. East Afr Med J. 2001;78(2):80-3.

34. Galmessa A. Assessment of prevalence, determinants, and effects of mental distress among Alemaya university students. Addis Abeba: Addis Abeba University; 2005.

35. Garoma S, Belachew T, Wondafrash M, Duke N, Sieving R, Pettingell S. Sexual coercion and reproductive health outcomes among young females of Nekemte Town, South West Ethiopia. Ethiop Med J. 2008;46(1):19-28.

36. Mooney A, Kidanu A, Bradley HM, Kumoji EK, Kennedy CE, Kerrigan D. Work-related violence and inconsistent condom use with non-paying partners among female sex workers in Adama City, Ethiopia. BMC Public Health. 2013;13:771.

37. Oljira S. Assessment of Workplace Violence Against Nurses Working in the Emergency Department of Referral Public Hospitals in Addis Ababa. Addis Ababa: Addis Ababa University; 2017.

38. Azanaw KA, Gelagay AA, Lakew AM, Teshome DF. physical violence and associated factors among housemaids living in Debre-Tabor Town, Northwest Ethiopia: does employer alcohol intake increase housemaid violence? Int J Reprod Med. 2019;2019:8109898.

39. Sheferaw ED, Kim YM, van den Akker T, Stekelenburg J. Mistreatment of women in Ethiopia's public health facilities. Reprod Health. 2019;16(1):130

40. Worku D, Gebremariam A, Jayalakshmi S. Child sexual abuse and its outcomes among high school students in southwest Ethiopia. Trop Doct. 2006;36(3):137-40

41. Kassahun T. Sexual harassment: the case of Jimma University. Addis Ababa: Addis Ababa University; 2009.

42. Philpart M, Goshu M, Gelaye B, Williams MA, Berhane Y. Prevalence and risk factors of gender-based violence committed by male college students in Awassa, Ethiopia. Violence Vict. 2009;24(1):122-36.

43. Molla M, Ismail S, Kumie A, Kebede F. Sexual violence among female street adolescents in Addis Ababa, April 2000. Ethiop J Health Dev. 2002;16(2):119-28.

44. Gessessew A, Mesfin M. Rape and related health problems in Adigrat Zonal Hospital, Tigray Region, Ethiopia. Ethiop J Health Dev. 2004;18(3):140-4.

45. Gebreyohannes Y. Prevalence and factors related to gender-based violence among female students of higher learning institutions in Mekelle Town, Tigray, Northern Ethiopia. Addis Ababa: Addis Ababa University; 2007.

46. Alemayehu M, Yohannes G, Damte A, Fantahun A, Gebrekirstos K, Tsegay $\mathrm{R}$, Goldberger A, Yebyo H. Prevalence and predictors of sexual violence among commercial sex workers in Northern Ethiopia. Reprod Health. 2015;12(1):47.

47. Galu SB, Gebru HB, Abebe YT, Gebrekidan KG, Aregay AF, Hailu KG, Abera GB. Factors associated with sexual violence among females administrative staff of Mekelle University, North Ethiopia. BMC Res Notes. 2020;13(1):15

48. Worku A, Addisie M. Sexual violence among female high school students in Debark, northwest Ethiopia. East Afr Med J. 2002;79(2):96-9.

49. Fitaw Y, Haddis K, Million F, Delil M, Yohannes M, Bekele N. Gender-based violence among high school students in northwest Ethiopia. Ethiop Med J. 2005:43(4):215-21.

50. Shimekaw B, Megabiaw B, Alamrew Z. Prevalence and associated factors of sexual violence among private college female students in Bahir Dar city, North Western Ethiopia. 2013.

51. Mullu G, Gizachew A, Amare D, Alebel A, Wagnew F, Tiruneh C, Worku M, Kediri R, Tamiru S, Demsie T. Prevalence of gender-based violence and associated factors among female students of Menkorer high school in Debre Markos town, Northwest Ethiopia. Science. 2015:3(1):67-74. 
52. Yenealem DG, Woldegebriel MK, Olana AT, Mekonnen TH. Violence at work: determinants \& prevalence among health care workers, northwest Ethiopia: an institutional-based cross-sectional study. Ann Occup Environ Med. 2019;31:8

53. Arnold D, Gelaye B, Goshu M, Berhane Y, Williams MA. Prevalence and risk factors of gender-based violence among female college students in Awassa, Ethiopia. Violence Vict. 2008;23(6):787-800.

54. Marsh J, Patel S, Gelaye B, Goshu M, Worku A, Williams MA, Berhane Y. Prevalence of workplace abuse and sexual harassment among female faculty and staff. J Occup Health. 2009;51(4):314-22.

55. Asfaw M. Sexual violence and its consequence among female night school students in Hawassa town, Southern Ethiopia: a cross-sectional study. Addis Abeba: Addis Abeba University; 2010.

56. Tora A. Assessment of sexual violence against female students in Wolaita Sodo University, Southern Ethiopia. J Interpers Violence. 2013;28(11):2351-67.

57. Bekele T, Deressa W. Experience of sexual coercion and associated factors among female students of Ambo University in Ethiopia. Sci J Public Health. 2014;2(6):532-8.

58. Letta T, Feleke A, Derseh L. Assessment of violence and associated factors among rural high school female students, in Hadiya zone, southern nation and nationalities peoples' region, Ethiopia, 2013. Open Access Libr J. 2014;1(3):1-14.

59. Takele A, Setegn T. Sexual coercion and associated factors among female students of Madawalabu University, Southeast Ethiopia. Adv Public Health. 2014;2014.

60. Fute M, Mengesha ZB, Wakgari N, Tessema GA. High prevalence of workplace violence among nurses working at public health facilities in Southern Ethiopia. BMC Nurs. 2015;14:9.

61. Nimani W, Hamdela B. Sexual violence and associated factors among high school students in Butajira town, South Ethiopia. Gen Med Open Access. 2015;2015.

62. Sendo E, Meleku M. Prevalence and factors associated with sexual violence among female students of Hawassa University in Ethiopia. Sci Postprint. 2015;1(2):e00047.

63. Tantu T, Wolka S, Gunta M, Teshome M, Mohammed H, Duko B. Prevalence and determinants of gender-based violence among high school female students in Wolaita Sodo, Ethiopia: an institutionally based cross-sectional study. BMC Public Health. 2020;20(1):540.

64. Bekele $A B$, Van Aken MA, Dubas JS. Sexual violence victimization among female secondary school students in eastern Ethiopia. Violence Vict. 2011;26(5):608-30

65. Gorfu M, Demise A. Sexual violence against schoolgirls in Jimma zone: prevalence, patterns, and consequences. Ethiop J Educ Sci. 2007;2(2):11-37.

66. Mamaru A, Getachew K, Mohammed Y. Prevalence of physical, verbal, and nonverbal sexual harassment and their association with psychological distress among Jimma University female students: a crosssectional study. Ethiop J Health Sci. 2015;25(1):29-38.

67. Mulugeta E, Kassaye M, Berhane Y. Prevalence and outcomes of sexual violence among high school students. Ethiop Med J. 1998;36(3):167-74.

68. Tadesse S. Assessment of sexual coercion among Addis Ababa University female students. Addis Abeba: Addis Abeba University; 2004.

69. Lelisa $G$, Yusuf L. A cross-sectional study on the prevalence of genderbased violence in three high schools, Addis Ababa, Ethiopia. Ethiop J Reprod Health. 2008;2(1):9-9.

70. Haile RT, Kebeta ND, Kassie GM. Prevalence of sexual abuse of male high school students in Addis Ababa, Ethiopia. BMC Int Health Hum Rights. 2013;13:24.

71. Jira C. Assessment of workplace violence prevalence and predictors against nurses working in the Oromia regional state's referral hospitals, Ethiopia. J Indian Manag Strat. 2015;20(1):61-4.

72. Abate A, Abebaw D, Birhanu A, Zerihun A, Assefa D. Prevalence and associated factors of violence against hospital staff at Amanuel Mental specialized hospital in Addis Ababa, Ethiopia. Psychiatry J. 2019;2019:3642408.

73. Amogne MD, Balcha TT, Agardh A. Prevalence and correlates of physical violence and rape among female sex workers in Ethiopia: a cross-sectional study with respondent-driven sampling from 11 major towns. BMJ Open. 2019;9(7):e028247.
74. Bekele T, Kaso M, Gebremariam A, Deressa W. Sexual violence and associated factors among female students of Madawalabu University in Ethiopia. Epidemiology (Sunnyvale). 2015;5(190):2161-5.

75. Lee H-E, Kim H-R, Park JS. Work-related risk factors for workplace violence among Korean employees. J Occup Health. 2013:13-0082-OA.

76. Basile KC, D'Inverno AS, Wang J. National prevalence of sexual violence by a workplace-related perpetrator. Am J Prev Med. 2020;58(2):216-23.

77. Oche OM, Adamu H, Mallam SA, Muhammad RAO, Aisha S. Assessment of knowledge, attitude and experience of sexual violence among female employees in Sokoto Metropolis, Northwest Nigeria. Afr J Reprod Health. 2020;24(2):164-75.

78. Van Berlo W, Ploem R. Sexual violence: knowledge file. In: Geraadpleegd op; 2019.

79. Guay S, Goncalves J, Jarvis J. A systematic review of exposure to physical violence across occupational domains according to victims' sex. Aggress Violent Beh. 2015;25:133-41.

80. Liu J, Gan Y, Jiang H, Li L, Dwyer R, Lu K, Yan S, Sampson O, Xu H, Wang C. Prevalence of workplace violence against healthcare workers: a systematic review and meta-analysis. Occup Environ Med. 2019;76(12):927-37.

81. Chen Z, Peek-Asa C, Yang G. Prevalence of and risk factors associated with workplace violence: a cross-sectional study in 7026 health staff in South China. Injury Prev. 2010;16(Suppl 1):A4.

82. Deering KN, Amin A, Shoveller J, Nesbitt A, Garcia-Moreno C, Duff P, Argento $E$, Shannon K. A systematic review of the correlates of violence against sex workers. Am J Public Health. 2014;104(5):e42-54.

83. Semple SJ, Stockman JK, Pitpitan EV, Strathdee SA, Chavarin CV, Mendoza DV, Aarons GA, Patterson TL. Prevalence and correlates of client-perpetrated violence against female sex workers in 13 Mexican Cities. PLoS ONE. 2015;10(11):e0143317.

84. Muldoon KA, Akello M, Muzaaya G, Simo A, Shoveller J, Shannon K. Policing the epidemic: high burden of workplace violence among female sex workers conflict-affected northern Uganda. Glob Public Health. 2017;12(1):84-97.

85. Beksinska A, Prakash R, Isac S, Mohan HL, Platt L, Blanchard J, Moses S, Beattie TS. Violence experience by perpetrator and associations with HIV/STI risk and infection: a cross-sectional study among female sex workers in Karnataka, south India. BMJ Open. 2018;8(9):e021389.

86. Beletsky L, Lozada R, Gaines T, Abramovitz D, Staines H, Vera A, Rangel G, Arredondo J, Strathdee SA. Syringe confiscation as an HIV risk factor: the public health implications of arbitrary policing in Tijuana and Ciudad Juarez, Mexico. J Urban Health. 2013;90(2):284-98.

87. Goldenberg SM, Engstrom D, Rolon ML, Silverman JG, Strathdee SA. Sex workers perspectives on strategies to reduce sexual exploitation and HIV risk: a qualitative study in Tijuana, Mexico. PLOS ONE. 2013;8(8):e72982.

88. Loza O, Strathdee SA, Lozada R, Staines H, Ojeda VD, Martínez GA, Amaro H, Patterson TL, Segura PM. Correlates of early versus later initiation into sex work in two Mexico-US border cities. J Adolesc Health. 2010;46(1):37-44.

89. Robertson AM, Syvertsen $J$, Amaro H, Martinez G, Rangel MG, Patterson TL, Strathdee SA. Cannot buy my love: a typology of female sex workers' commercial relationships in the Mexico-US border region. J Sex Res. 2014;51(6):711-20.

90. Servin AE, Brouwer KC, Gordon L, Rocha-Jimenez T, Staines H, VeraMonroy RB, Strathdee SA, Silverman JG. Vulnerability factors and pathways leading to underage entry into sex work in two Mexican-US border cities. J Appl Res Child Informing Policy Child Risk. 2015;6(1).

91. Strathdee SA, Lozada R, Martinez G, Vera A, Rusch M, Nguyen L, Pollini RA, Uribe-Salas F, Beletsky L, Patterson TL. Social and structural factors associated with HIV infection among female sex workers who inject drugs in the Mexico-US border region. PLOS ONE. 2011;6(4):e19048.

92. Henning MA, Zhou C, Adams P, Moir F, Hobson J, Hallett C, Webster CS. Workplace harassment among staff in higher education: a systematic review. Asia Pacific Educ Rev. 2017;18(4):521-39.

93. Rahama MR, Jahan N. Sexual harassment in South Asia: a comparative study on Bangladesh, India, Nepal, and Srilanka. IOSR J Bus Manag. 2015;17(6):49-57.

94. Hutagalung F, Ishak Z. Sexual harassment: a predictor of job satisfaction and work stress among women employees. Procedia-Soc Behav Sci. 2012;65:723-30. 
95. Hejase HJ. Sexual harassment in the workplace: an exploratory study from Lebanon. J Manag Res. 2015;7(1):107-21.

96. Richman JA, Rospenda KM, Nawyn SJ, Flaherty JA, Fendrich M, Drum ML, Johnson TP. Sexual harassment and generalized workplace abuse among university employees: prevalence and mental health correlates. Am J Public Health. 1999;89(3):358-63.

97. Bondestam F, Lundqvist M. Sexual harassment in higher education-a systematic review. Eur J High Educ. 2020:1-23.
98. McMahon S. Call for research on bystander intervention to prevent sexual violence: the role of campus environments. Am J Community Psychol. 2015;55(3-4):472-89.

\section{Publisher's Note}

Springer Nature remains neutral with regard to jurisdictional claims in published maps and institutional affiliations.
Ready to submit your research? Choose BMC and benefit from:

- fast, convenient online submission

- thorough peer review by experienced researchers in your field

- rapid publication on acceptance

- support for research data, including large and complex data types

- gold Open Access which fosters wider collaboration and increased citations

- maximum visibility for your research: over $100 \mathrm{M}$ website views per year

At BMC, research is always in progress.

Learn more biomedcentral.com/submissions 